\title{
Effect on Road Safety by Roadway Condition, Traffic and Manmade Features
}

\author{
Arpit Jaiswal \\ PG Student, Civil Engineering Department,, \\ Jawaharlal Institute of Technology Borawan, Madhya Pradesh, India \\ Atul Bhatore \\ Asst. professor, Civil Engineering Department, \\ Jawaharlal Institute of Technology Borawan, Madhya Pradesh, India
}

\begin{abstract}
India is a leading developing country and road safety is still in a premature stage. Accident severity is growing in rapid order due to increasing in vehicle population. Accident leads to disablement, damage to health and property, death of human or animals' social suffering and general degradation of environment. The road accident situation in India is vibrating. Records from year 2014 show that there is one death at every 3.75 minutes because of road accidents. The high accident rate is largely considered to the inadequacy of the highways and other main roads to meet the traffic demands, road user behaviour, vehicular defects, poor road geometrics and inadequate visibility. Road accidents results in heavy wealth loss to the country. Road Safety is necessary to reduce accident involving both human element and vehicles there by developing the road safer and user friendly to traffic.

In Madhya Pradesh state area around our district headquarter Khargone roads has major connectivity and there are not big industries but these road carries large numbers of passengers to industrial area of Indore and Gujarat.
\end{abstract}

Keywords - ACCIDENT, DRIVER, ROAD SAFETY, TRAFFIC DENSITY, TRAFFIC VOLUME

\section{INTRODUCTION}

Road accident takes away the life of 3398 peoples every day. This is global humanitarian disaster, and it is manmade (Global Road Safety Partnership Annual Report (GRSPAR-2014).

Road safety is most important problem in our society. By Year -2014 rate of death in road accident is 2.24 million per year and about 50 million peoples were injured every year. About $50 \%$ of all road death are among pedestrian, cyclist or motorcycle riders. in 2014 Indian roads were at their dead list claiming more than 16 lives every hour on average. Over 1.41 lakh people died in crashes, 3\% more than the number of fatalities in 2013.

If the current trends of road accident continue than it is predicted to be third leading contributor to global burden of diseases and injury by 2020.now traffic accident are at 8th position globally. India having more number of fatalities recorded by road accidents in the world had earned the dubious distinction. Road safety is emerging as major social concern around the world especially in India. Accidents are somewhat a drain on the national economy and may lead to disablement, damage to the health and property, death, social suffering and general environmental degradation.

To minimize the number of crashes by any kind and a road safety is the severity expected to takes place on the entity during a specific period. Accidents and the fatalities on road are also the result of reciprocity of a number of factors. Road users in India are heterogeneous in nature, ranging from pedestrians, cycles, rickshaws, animal- driven carts, hand carts ,bullock carts and tractor trolleys, to various categories of two wheelers or three wheelers, cars, buses, trucks, and multi-axle commercial vehicles etc., The vehicle population has been steadily increasing because of changes in lifestyle of society. There are development in vehicle population with limited road space used by a various variety of vehicles has increase the need and urgency for a well thought-out policy on the issue of road safety. In India growth of vehicle population is directly proportional to the rate of accident.

Road accidents are a human tragedy, which is directly related to high human suffering. They impose a huge socioeconomic cost in terms of injuries, untimely deaths, and loss of potential income. The ramifications of road accidents can be colossal and negative impact of road accident is felt not only on individuals, their health and welfare, as well as on the economy. Consequently, it has become an issue of national concern. Road Safety is a multi-sectored and multi-dimensional issue. It includes the development as well as management of road infrastructure, provision of safer vehicles, urban land use planning, legislation and law enforcement, provision of health and hospital services, child safety, mobility planning, etc In other words, its having spans engineering aspects 
of both, roads and vehicles on one hand and the provision of health and in post-crash scenario hospital services should available for trauma cases

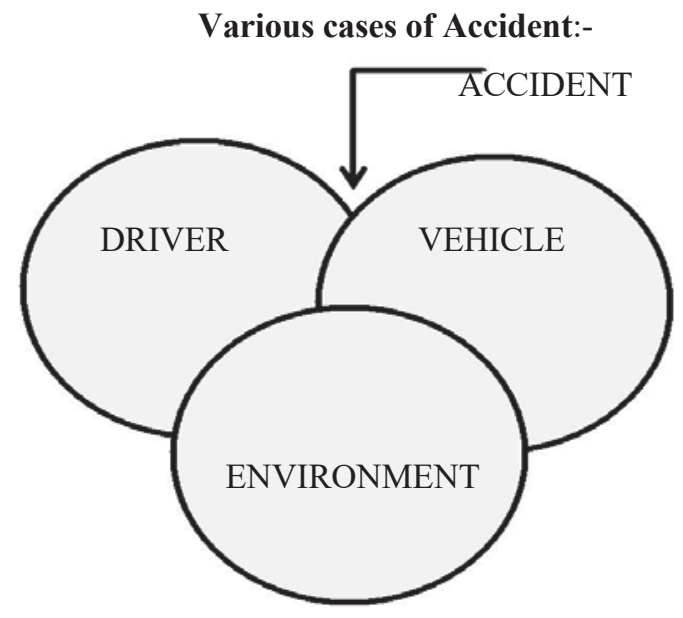

Table 1.0- Various Causes of Road Accident

\begin{tabular}{|l|l|}
\hline \multicolumn{2}{|c|}{ DRIVER RELATED } \\
\hline Alcohol \& drugs & Sickness \\
\hline Unsafe speed & Cell phones Use \\
\hline Drowsing or Fatigue & Distraction \\
\hline Improper passing or turning & Disregard Traffic controls \\
\hline Non Use of Restraint & Eye problem \\
\hline \multicolumn{2}{|c|}{ VEHICLE RALATED } \\
\hline Over Loading & Steering Defect \\
\hline Brake Defect & Tire Failure \\
\hline Light Defect & Improper Wheel Alignment \\
\hline & Vision -Obstruction \\
\hline Road Side Hazard & Improper Traffic Control \\
\hline Ruts/ Shoulder Defect & Improper / Nonworking traffic control \\
\hline Debris or Garbage on The Road & \\
\hline Fixed Object & Glare \\
\hline Water ponding & Smoke or Fog \\
\hline
\end{tabular}

Table 2.0 - Types of Accident, Position of Vehicles and Consequences

\begin{tabular}{|l|l|}
\hline \multicolumn{1}{|c|}{ Type of Accident } & \multicolumn{1}{c|}{ Position of Vehicle } \\
\hline Head On & Vehicle From Opposite Direction \\
\hline Rear End & Vehicle In Same Side \\
\hline Angle and Turning & Vehicle from Adjacent Direction (Intersection) \\
\hline Parking or Backing & Overturning \\
\hline Roll Over & On path \\
\hline Run-off Road & Off Path \\
\hline Moped Bike & On Curve Turning \\
\hline
\end{tabular}




\begin{tabular}{|l|l|}
\hline Fixed Object (Trees \& Poles) & Off Path Curve \\
\hline Pedestrian & Any Position \\
\hline Animal & Any Position \\
\hline \multicolumn{2}{|c|}{ Consequences } \\
\hline Property Loss & Contusion (Head Injury Without Skin Unbroken) \\
\hline Spot Death & Fracture \\
\hline Loss of Consciousness & Freezing \\
\hline Amputation (Loss of One or More Limb) & Trauma \\
\hline Head / Neck Injury & Laceration(Injury Involving Cut) \\
\hline Abrasion & Vision/Speech/Hearing Impairment \\
\hline Sprain (Ankle/Joint Twist) & Chest Pain/Respiratory Impairment \\
\hline
\end{tabular}

\section{OBJECTIVES OF THE PROPOSED STUDY}

Expansion in the road network, growth in motorization and a rising population of a country contribute towards increasing numbers of road accidents, road numbers of registered motor vehicles in the country and the country's population have rising at a compound annual growth rate (CAGR) of 3.4 per cent, 9.9 per cent and 1.6 per cent, respectively, during the decade 2002 to 2011. During the same period, the number of road accidents in the country increased at a CAGR of 2.1 per cent. also the number of road accident fatalities and the number of persons injured in road accidents in the country between 2002 and 2012 increased by 5.8 per cent and 2.4 per cent, respectively. Very little work has been done in India to analyze accidents on two-lane roads.

The main objectives of the study work are:-

(i) To study the annual, monthly, daily and hourly variation in accident rate on selected Stretch of urban twolane road

(ii) To study the effect of traffic volume, traffic density and traffic capacity of roadway on accident rate on urban Two-lane road.

(iii) To study the maintenance of road surface and cross-sectional element on rate of accident.

(iv) To develop an accident prediction model based on AADT, road condition, road side Features.

\section{LITERATURE REVIEW}

Many factors may exhibit a measurable influence on driving behaviour and traffic safety on two-lane highways; these include, but are not limited to

(i) Human factors such as improper judgment of road ahead and traffic, driving under the influence of alcohol or drugs, driver education and experience, young driver, age and sex.

(ii) Traffic factors like speed, volume, density, capacity, traffic mix and variation.

(iii) Vehicle deficiencies, such as defective brake, headlight, tyres, steering and vehicle condition.

(iv) Road condition like slippery or skidding road surface, ravels, pot hole, ruts etc.

(v) Road design such as inadequate sight distances, shoulder width, no of lanes, improper curve design, improper lighting and traffic control devices.

(vi) Weather condition like fog, heavy rainfall, dust, snow etc

(vii) Other causes are such as incorrect sign signals, service station, badly located advertisement, stray animals.

\section{A- Driver Characteristics}

(i) AGE, GENDER AND PERSONALITY 
at Hassan and Aty (2012) studied 680 young driver behaviour involvement in traffic crash in Florida. The result revealed that aggressive violation, in-vehicle distraction and demographic characteristics were the significant factors affecting young drivers involvement in crashes at the age of 16-17.Invehicle distraction, attitude towards speeding and demographic characteristics were the significant factors effect young drivers crash risk at the age of 18-24. Constantinou et al.,(2011) found that young novice driver $(<25$ yrs. $)$ are in high risk related to traffic offence. The study was based on gender, sex, age and personality.

\section{(ii) PERCEPTION}

Sagberg and Bjornskau (2006) conducted a video-based hazard perception test and concluded that male novice driver had relatively longer reaction time and initial risk involved. Deery (1999) studied about hazard and risk perception among young novice driver and concluded that hazard and risk perception are fundamental skill that young drivers need to develop.

\section{(iii) ALCOHOL AND DRUGS}

In 2012 shivkumar and krishnaraj, Alcohol causes deterioration of driving skills even at low levels and the probability of accidents increases with rising blood alcohol levels. Alcohol needs no digestion and is absorbed rapidly into the blood stream; about $10 \%$ to $15 \%$ of alcohol users develop alcohol dependence and become alcoholics. After drinking, the judgment power of the driver gets impaired which is a threat to road safety. Due to its effects, driver tends to take more risks, becomes more aggressive and takes a longer reaction time. The relative probability of causing accidents increases with the rising blood alcohol levels keeping road safety at stake.).

\section{(iv) SPEED}

Aarts and Schagen (2006) studied relationship between speed and risk of a crash. The conclusion was when speed increases crash increases.

Lee at al.,(2006) developed a real- time crash prediction model by taking total travel time and Crash potential reduction. The study result indicated the variable speed limit could reduce crash potential by $5-17 \%$. Prabhakharn et al.,(2011) analyzed that imparting training among drivers reduces speeding behavior.

Houquani et al.,(2012) investigated hospitalized drivers who were involved in road traffic collision between April 2006 to October 2007 in UAE.A logistic model was fitted using the variables like drivers demographic data, time, date, location, mechanism of collision, speed at collision and sleepiness. The conclusion was sleep is an important factor to road traffic collision. Further they advised to discontinue driving on highways feeling sleepy especially during lunar month of Ramdan. They used speed as dependent variable and distance as function in ANOVA.

\section{(v) FATIGUE}

Blower et al.,(1998) observed that $20 \%$ of all fatal crash and $10 \%$ of all injuries involving truck occurred between $12 \mathrm{AM}$ to $6 \mathrm{AM}$, the peak period for driver fatigue.

\section{(vi) CELL PHONES}

Tornros and Boiling (2005) conducted an experiment with 48 drivers by covering a distance of $15 \mathrm{Km}$ on a rural two-lane road. They concluded that driving performance reduced by dialling hand held phone and speed decreased with hands free phone. Reaction time to warning sign at road side decrease for hand held phone user

\section{B- VEHICULAR CHARACTERSTICS}

Vehicle plays an important role in a crash. This may be due to defective wheel alignment, tyre bursting, brake failure, overloading, one or two head light defect, back light defect, indicator defect, steering defect.

\section{(i) TYRE DEFECT}

Tyre defect may be due to under or over inflation, overloading, ageing behavior, external impact due to pothole, debris, nail etc. Tires up to six years from the date of manufacturer should be changed including spare tires (Osueke and Okorie,2012)

\section{(ii) BRAKE FAILURE}

Accident imposes high intangible cost (pain, grief and suffering).Vehicle accident can be fatal and constitute a high economic burden. Oduro (2012) surveyed a no of accident and found that $83 \%$ break failure result in accident. Brake ineffectiveness is due to vehicle overloading, uneven tyre pressure, incorrect brake adjustment, air in 
breaking system, automatic brake adjuster not working, brake fluid on lining .Brake failure is due to broken pipe, low brake fluid level, cracked brake drum, brakes overheating.

\section{(iii) OVERLOADING}

One overloaded axle causes damage equivalent to 22 legally loaded axles. Overloaded vehicle increases maintenance cost and hazard (Osama et al., 2012) Overloading truck reduces braking ability of truck, stability of truck, unexpected defect of road and damage of vehicle. Fatal crashes involving overloaded large truck increases by $52 \%($ Chan, 2008)

\section{C- ENVIRONMENT CHARACTERISTICS}

\section{(i) ROAD ELEMENTS}

Roadway design is one of the most significant factors that affect driving behavior and perceived safety. Bassat and Shinar (2011) studied combined effect of roadway design element such as shoulder width, guardrail and roadway geometry (curvature) by taking objective driving measures (speed and lane position) and subjective measure(perceived safe driving speed and estimated road safety) into account. They found the shoulder width had a significant effect on actual speed and lane position but when a guard rail had a significant effect on perceived safe driving.

Zegeer et al.,(1991) studied the relationship between lane or shoulder widening and accident reduction rate. He concluded that $21 \%$ reduction in accident can be achieved by widening the lane 4 feet per side

\section{(ii) SURFACE DISCONTINUITY}

Forest et al.,(2009) established a relationship between accident data and surface discontinuities(pavement edge drops, pavement ruts, potholes etc.)

\section{(iii) ROAD SIDE FEATURES}

Somchainuek et al., (2013) investigated road side safety on Thai NH. The result showed that speeding vehicles were involved in roadside crashes accounted for about $70 \%$ of the total crashes and $30 \%$ of road side crashes were due to road side trees. Jinsun and Doohee (2003) established a relationship between accident severity and roadside features.

\section{(iv )SIGNS AND SIGNALS}

Chen et al., (2011) developed traffic safety model using regression in New York city. The result shows that signal related countermeasure that are designed to reduce conflict are split phase, timing, signal installation, all pedestrian phase and increasing pedestrian crossing reduces crashes. Traffic calming measures including road diets are also found to be significant in safety benefits. Countermeasures that are designed to alert driver cognitive attention such as high visibility crosswalks and posted speed limit reduction signs appear to have lesser effect.

\section{(v) FOG AND SMOKE}

Mohmed et al., (2011) studied on crash related to visibility obstruction due to fog and smoke in Florida. It was found that fog smoke related crashes are more likely to occur at night without street lighting leading to more severe injuries. Head-on and Rear-end are common crashes in terms of crash risk and severity. These crashes are more prevalent on high speed road, undivided roads, roads with no sidewalks and two lane rural roads.

\section{(vi) VOLUME}

Hiselius(2004) studied the accident frequency and homogeneous flow of vehicle. It was found that the accident rate decreases when the traffic flow is homogenous in nature. For Lorries there was an decrease in no of accident and for car the accident rate was constant.

Golob et al.,(2004) made a relation between traffic flow and traffic accident. It was from the study that means volume and median speed affect safety. Lane- change crashes tend to occur when there is the highest variability in speed. While rear end crashes tend to cluster where there is a lower variation in speed. There suggestion was to improve traffic engineering and implementation of ITS (Intelligent Transportation System) and enhance driver education. 
Kurlaftis and Golias (2002) studied between road geometric characteristics and accident rate. They found AADT, lane width, Serviceability index, friction, pavement type, access control are the main factor contributing to accidents. Relative importance was $100 \%$ for AADT, $72 \%$ for lane width, $59 \%$ for serviceability, $35.6 \%$ for friction, $30 \%$ for pavement type and $14 \%$ for rural two-lane road

Good LOS tends to occur at night when volumes are low. Single vehicle crash rate is higher because more drivers are drowsy or less alert. When traffic volume is heaviest multi-vehicle crashes are likely to occur (Ivan et al., 2004).

Caliendo et al.,(2006) fitted a Poisson and negative binomial model using accident as dependent variable and length, curvature, sight distance, side friction coefficient, longitudinal slope, presence of junction as independent variable.

Zhuanglin(2009) fitted a multiple logistic relationship between accident severity and a series of potential factors likeCross section, pavement type, accident location, traffic environment, traffic environment, lighting. He found that major accident was on expressway as compared to Arterial Street.

\section{PROPOSED METHODOLOGY}

Selected road for the Study:-

(i) Khargone To Kasrawad Road (35.6 Km.)

(ii) Khargone to Sanawad road $(58.4 \mathrm{Km}$.)

(iii) Khargone to Julwaniya road (48 Km.)

(iv) Khargone to Bhagwanpura $(22.8 \mathrm{Km})$

(v) Khargone to bhikangaon $(40.1 \mathrm{Km})$

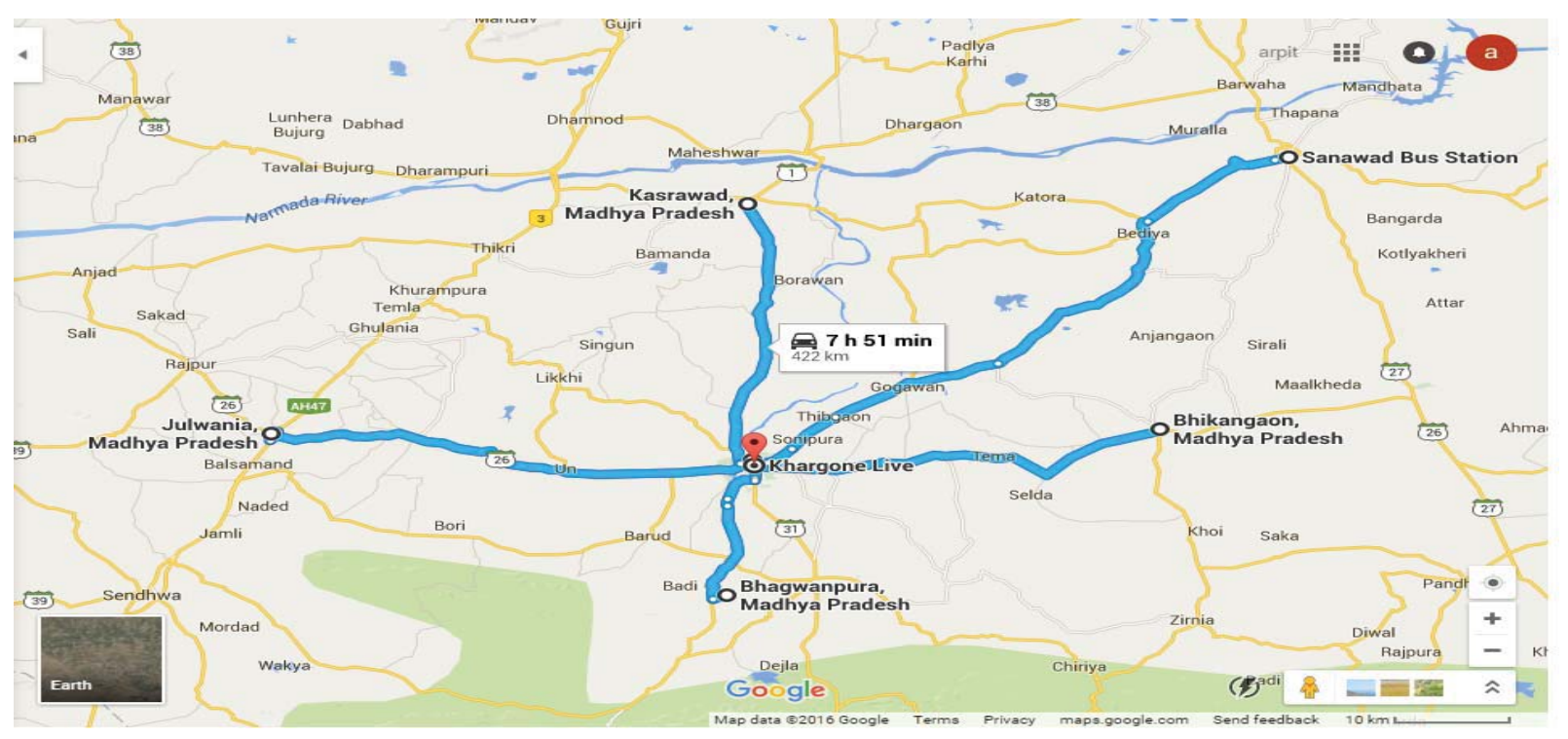

Fig. :- Study Area, Source:- Google Map

\section{A- Collection Of Data From Police Record}

The application is given to the S.P. KHARGONE regarding the collection of data of accident from S.P. office Khargone.

The police stations have their own FIR records of several years. The data from these records of last ten years were extracted from the FIRs filled under IPC NO.279/337/338/304 (A).

\begin{tabular}{|l|l|}
\hline \multicolumn{1}{|c|}{ Police Station } & \multicolumn{1}{|c|}{ Area Covered Under The Police Station } \\
\hline Khargone & Near Khargone \\
\hline
\end{tabular}




\begin{tabular}{|l|l|}
\hline Kasrawad & Kasrawad To Maingaon \\
\hline Gogawan & Jetapur To Rodiya \\
\hline Bediya & Rodiya To Satajana \\
\hline Bhagwanpura & Bhagwanpura ToKhargone \\
\hline Segaon & Khargone To Segaon \\
\hline Sanawad & Satajna To Sanawad \\
\hline Maingaon & Khargone Maingaon \\
\hline Bhikangaon & Khargone To Bhikangaon \\
\hline
\end{tabular}

B- Collections Of Data From P.W.D. (PUBLIC WORK DEPARTMENT)

\begin{tabular}{|c|c|}
\hline Width of carriage way in Mt. & 7 \\
\hline Width of formation in Mt. & $\mathbf{1 2}$ \\
\hline Width of Land in Mt. & $\mathbf{4 5}$ \\
\hline
\end{tabular}

\section{EXPECTED OUTCOME}

Following Outcome are expected:-

(i) Determination of accident rate and frequency of accident

(ii) Annual variation in accidents.

(iii) Monthly Variation in Accidents.

(iv) Hourly variation in accidents.

(v) Number, Category Of Vehicle Involve In Fatalities.

(vi) To establish Relation between the traffic volume and accident.

(vii) Identification of road surface conditions along the black spot.

(viii) To compare trend of accident, injuries and fatalities. Identification of road side feature involve in accident.

\section{REFERENCES}

[1] Global Road Safety Partnership Annual Report (2011) . http://www.grsproadsafety.org/sites/grsp.drupalgardens.com/files.

[2] Accidental deaths in ndia (2014), National Crime Records Bureau, Ministry of Home Affairs, Government of India, New Delhi.

[3] New geometric design consistency model based on operating speed Profiles for road safety evaluation, Accident Analysis and Prevention Article in press AAP-2915 pp.1-10

[4] Sivakumar, .Krishnaraj(2012),Road Traffic Accidents (RTAs) Due To Drunken Driving In India, Challenges In Prevention international journal of research in management and Technology,ISSN:2249 9563 VOL. 2, pp.401-406

[5] Hassan and Aty(2012) Exploring the safety implications of young drivers attitudes and perceptions, Accident Analysis and Prevention Vol.43 pp.45-65.

[6] The Effect of Pavement Condition on Traffic Safety: A Case Study of Some Federal Roads in Bauchi State A. Mohammed1, S. Y. Umar,D. Samson and T. Y. Ahmad. Department of Civil Engineering, Abubakar Tafawa Balewa University, Bauchi,P. M. B 0248 Bauchi, Bauchi State Nigeria.

[7] Somchainuek et al.,(2013) Investigation Roadside Safety on Thai National Highways Indian Journal of Science and Technology vol.6 issue 1.

[8] http://en.wikipedia.org/wiki/Haddon_Matrix.

[9] Prabhakharan et al.,(2012)Impairment of a speed management strategy in young drivers under high cognitive work load Accident Analysis and Prevention Vol.47 pp.24-29.

[10] Tornros and Boiling(2005)Mobile phone use -Effects of handheld and hands free phones on driving performance Accident Analysis and Prevention Vol.37 pp.902-909.

[11] Mohamed et al.,(2011)A study on crashes related to visibility obstruction due to fog and smoke, Accident Analysis and Prevention Vol.43,pp.1730-1737.

[12] Rio et al(2001) Alcohol, illicit drugs and medicinal drugs in fatally injured drivers in Spain between 1991and 2000Forensic Science International vol.127 pp.63-70. 
[13] Lee and Mannering(2002) Impact of roadside features on the frequency and severity of run-off-roadway accidents: an empirical, analysis Accident Analysis and Prevention vol.34 pp.149- 161

[14] Boni et al(2010), factors associated with alcohol and drug use among traffic crash victims in southern Brazil Accident Analysis and Prevention Vol.43 pp.1408-1413.

[15] Jinsun and Doohee(2003)Run-off-Roadway Accident Frequency Models By Type of Accident Severity Journal of the Eastern Asia Society for Transportation Studies, Vol.5, October, 2003.

[16] Longo et al(1999)The prevalence of alcohol, cannabinoids, benzodiazepines and stimulants amongst injured drivers and their role in driver culpability, Accident Analysis and Prevention Vol.32 pp.623 - 632 